\title{
Research on Information Development of Innovation and Entrepreneurship Education for University Students Based on Wireless Communication
}

\author{
Xin Yang \\ College of Technology and Business, Shandong Management University, Jinan, China
}

\begin{abstract}
Wireless communication and innovation and entrepreneurship education is undoubtedly one of the current hot issues in the field of human resource development and education. One emphasizes the change of educational technology, means and methods from the micro level; the other highlights the social significance of educational themes and contents from the macro level. Research on both aspects has entered the initial stage in China, and is still in the transition from conceptual analysis, origin exploration, and importance elaboration to the discussion of principles, methods and paths for the construction of the practical system, and remains at the level of academic discussion within the higher education system. At present, there is still a lack of industrialization models and platforms for applying theories to practice, as well as research and practice of applying new wireless communication technologies to the cultivation of innovative and entrepreneurial talents. Therefore, it is necessary to rely on the wireless communication platform, integrate big data technology, and make use of micro courses and MOOCs to break through the traditional cultivation mode of innovative and entrepreneurial talents in schools, and build a hybrid and intelligent enterprise-level learning management and talent management platform based on O2O. The platform can provide one-stop innovation and entrepreneurship education solutions for college students and young people, so as to promote the reform of innovation and entrepreneurship talent training mode in the mobile Internet era. It has a strong practical guiding significance for the research of wireless communication and innovation and entrepreneurship education.
\end{abstract}

Keywords: wireless communication;Innovation and entrepreneurship education;Development Research

\section{Introduction}

From the perspective of educational technology, mobile Internet has comprehensively and profoundly influenced the current educational concept, model and trend, and has great practical significance for improving the quality of education, promoting educational equity, and building a learning-oriented society and a state with a large pool of competent professionals. From the perspective of education theme, the 21 st century is undoubtedly the "era of innovation and entrepreneurship education", and the core competitiveness of the country is increasingly expressed in the cultivation, allocation and regulation of human resources and intellectual achievements, as well as the cultivation of the ability to develop, own and apply intellectual property rights. At no time in contemporary China is there a greater need to foster a sense of innovation and entrepreneurship than today[1].

\section{The current situation of innovation and entrepreneurship education}

The contents of studying innovation and entrepreneurship are essentially related. Innovation is the precursor and foundation of entrepreneurship; entrepreneurship is the carrier and manifestation of innovation. Therefore, innovation education and entrepreneurship education overlap to a large extent, and both need to cultivate people with innovative spirit and practical ability. Innovation and entrepreneurship education first originated in the United States after World War II, and there are about three models of its development: the first is the focus model. The School of Business is in charge of the management of entrepreneurship education, aiming at discipline construction and training practical management experience. It is mainly aimed at business school students, such as Harvard University. The second is the magnet pattern. Also, business schools or management schools are in charge of the management of entrepreneurship education, which aims to improve students' entrepreneurial literacy and entrepreneurial ability, such as Babson School of Business, MIT, etc. The third is the radiation mode, which aims at

ISSN: 0010-8189

www.converter-magazine.info 
cultivating students' entrepreneurial spirit and improving personal entrepreneurial skills. Its curriculum, resources and teachers are managed by different colleges, such as Cornell University [2]. At present, there are three modes of innovation and entrepreneurship education in China: the first is the mode of independent college. For example, Tsinghua University, Zhejiang University and Shanghai Jiao Tong University have set up independent entrepreneurship schools, focusing on improving students' entrepreneurial knowledge and skills. The second is the "first class + second class" model. Relying on relevant majors, colleges set up the direction of entrepreneurship education, combine entrepreneurship education with professional education, and devote themselves to cultivating high-quality talents with innovation, creation and entrepreneurial ability, such as Renmin University of China. The third is the collaborative model. The youth League Committee, employment center, student affairs office and other departments set up an entrepreneurship education platform, focusing on the comprehensive cultivation of entrepreneurship awareness, entrepreneurial ability and entrepreneurial quality, such as Peking University, Wuhan University, etc[3].

\section{Research status of wireless communication}

Both wireless communication and innovation and entrepreneurship education are undoubtedly one of the current hot issues in the field of human resource development and education. One emphasizes the change of education technology, means and methods from the micro level; the other highlights the social significance of education topics and contents from the macro level[4]. At present, the research on both aspects is in its initial stage in China, and is still in the transition from concept analysis, origin exploration, and importance elaboration to the discussion of principles, methods and paths of practice system construction. In particular, the current domestic innovation and entrepreneurship education model is still mainly based on traditional classroom lectures, with outdated concepts, lagging theories, rigid contents, monotonous forms, lack of practice, and basic uselessness of what students have learned. We believe that the application of wireless communication technology and micro-course mode to the field of innovation and entrepreneurship education can change the traditional classroom education mode, change professional education to general education, change formal learning to general learning, to make up for the shortcomings of traditional education. This is a model innovation. It is the theoretical basis of wireless communication technology[5-6].

\section{Basic structure of innovative and entrepreneurial talent training mode}

At present, wireless communication has attracted much attention at home and abroad, and wireless communication has been regarded as the key development direction of future network learning abroad. At present, the starting point of relevant research in China is still relatively low, the research scale is relatively small, and it is still in the initial stage. For example, the pilot project of the Higher Education Department of the Ministry of Education -- "Theory and Practice of Mobile Education" is undertaken by the Education Laboratory of the Modern Education Center of Peking University, the first mobile education laboratory in China. In addition, there are three universities participating in the Ministry of Education's "Mobile Education" project, including Peking University, Tsinghua University and Beijing Normal University[7-8].

The core content of the "Mobile Education" project is twofold: on the one hand, the "Mobile Education" information network is established. It will provide information services on education and research, teaching and management, and life information to teachers, students and staff, and enable them to enjoy better and more favorable mobile services. On the other hand, we will establish a system of "mobile education" service stations. Mobile education service stations will be set up at major universities to provide a variety of services and related products to users of the mobile education project. All this shows that wireless communication technology is changing the traditional learning and education model of human beings, and it also highlights that human beings are still in the beginning and exploratory stage of how to apply this new technology to the transformation of education.

On the basis of learning from the successes and failures of existing models, the research object of this paper "WINNOVO", relying on the wireless communication platform, integrates big data technology, and makes use of the

ISSN: 0010-8189 
forms of micro-courses and MOOCs to break through the traditional training mode of innovative talents in schools and build a hybrid and intelligent enterprise-level learning management and talent management platform based on O2O. Thus, it can provide one-stop innovation and entrepreneurship education solutions for college students and young people. To be specific, the basic framework of the research mainly includes three parts, as shown in Figure 1:

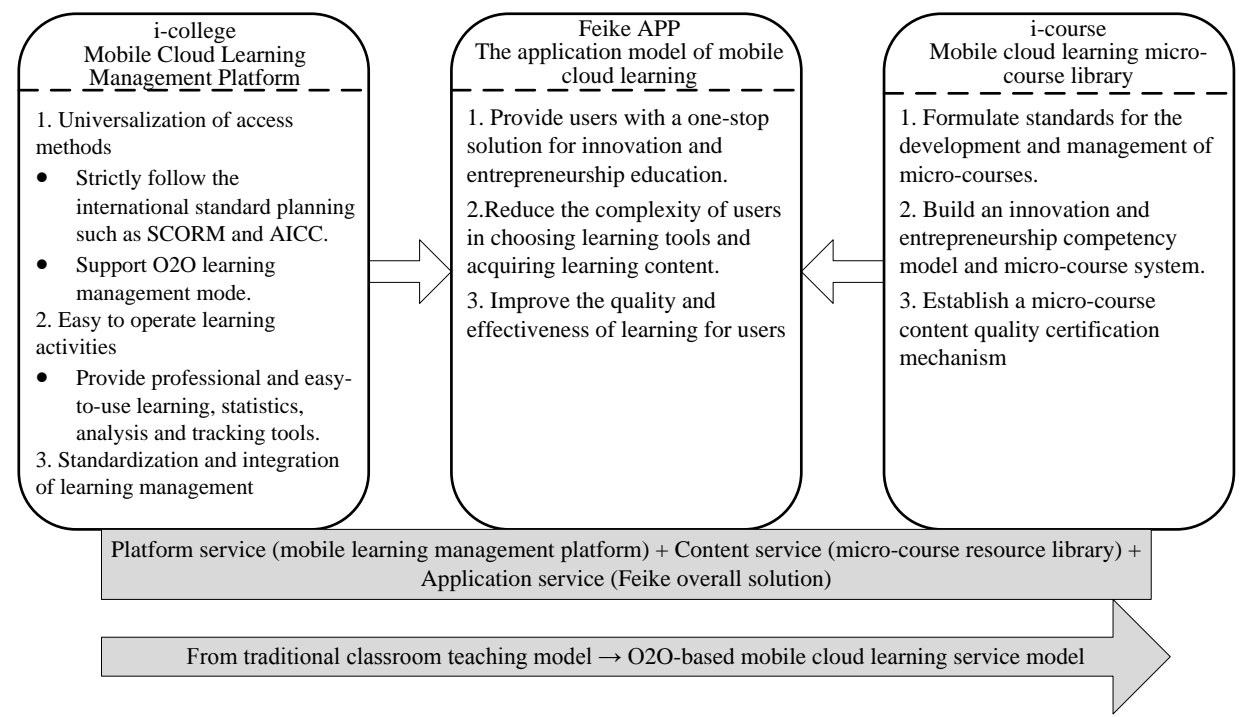

Figure1. The basic structure of O2O-based innovation and entrepreneurship training model

3.1 Innovation and entrepreneurship education services based on wireless communication management platform

The platform is an enterprise-level wireless communication platform based on M-Learning 2.0 mobile interactive learning concept and $\mathrm{O} 2 \mathrm{O}$ application mode, and fully compatible with An-droid/IOS operating systems, based on the characteristics of mobile Internet learning and innovation and entrepreneurship talent cultivation. It should not only realize the requirements of collaborative learning and massive knowledge resource sharing among large-scale users, but also significantly enhance the learning experience and effect, and effectively solve the shortcomings in the traditional education model involving talent cultivation process. The platform ultimately aims to assist all kinds of users and achieve the following application goals: (1) universal access to learning: it can reduce the cost of learning for learners, simplify the process of learning activities, and allow more people to participate in learning activities; (2) diversification of learning content and resources: it can give learners more opportunities to choose and take advantage of the sharing of online learning resources; (3) fragmentation of the learning process: it caters to the learning characteristics, fast-paced life and the rise of ubiquitous learning make fragmented learning a normalization; (4) Standardization and integration of wireless communication management: fragmentation of learning is not equal to fragmentation of knowledge. In the era of mobile Internet learning, the problems caused by knowledge fragmentation and information overload need to be solved. And the establishment of standardized management of content, process and assessment can not only bring into play the advantages of learning in the Internet era, but also overcome the negative effects brought about by the lack of systematic knowledge and information overload.

\subsection{Establishing a resource base for innovation and entrepreneurship education}

By establishing "mobile micro-course resource development and management standards" with wide compatibility, we realize the definition of the standard framework, development specifications and structural features for mobile micro-course development, so as to support the construction of standardized micro-course content resources and offline learning user experience to the greatest extent.

Finally, the following goals should be achieved: (1) Advanced technology: it facilitates rapid sharing and dissemination in the mobile Internet mode; (2) Scientific system: the course system, course map and learning route 
fully meet the needs of training innovative and entrepreneurial talents, while having good compatibility and expandability; (3) Openness of the model: It adopts open and standardized course access mechanism, widely attracts the participation of training institutions and industry experts, effectively integrates third-party resources, and realizes the maximum sharing of resources; (4) Standardization of the course: A content certification mechanism is established to ensure the quality of the course content; (5) Timeliness of the content: It ensures that the course content can closely match the user's work needs and can improve work performance, as shown in Figure 2.

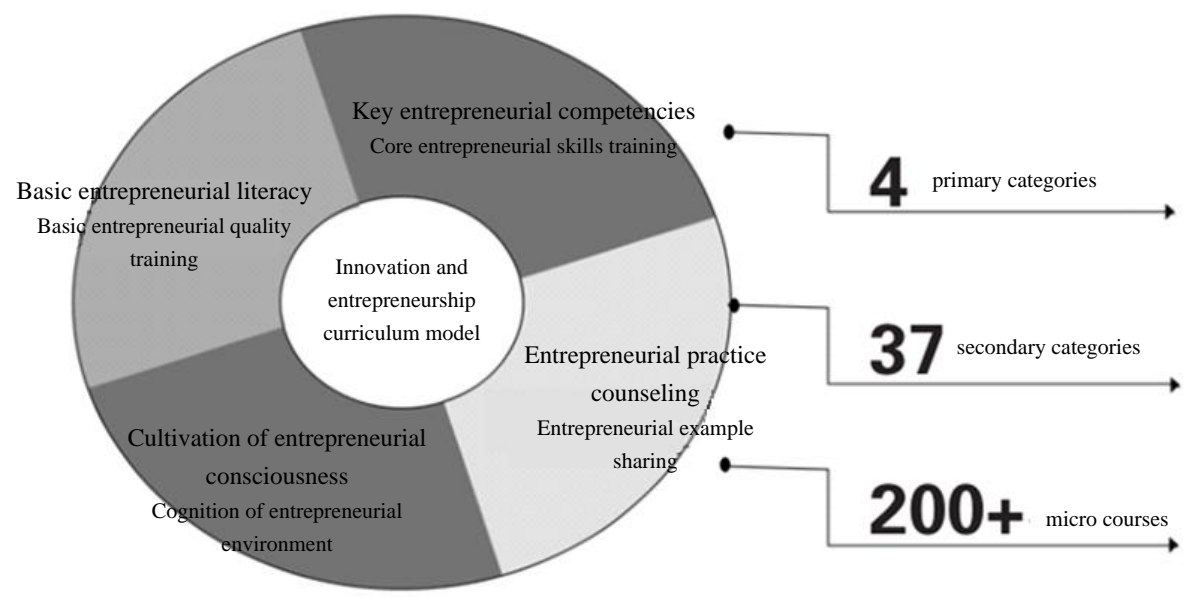

Figure2 "Four-in-one" micro-course system based on innovation and entrepreneurship skills

\subsection{Personalized services and system solutions for innovation and entrepreneurship}

According to different users' own characteristics, we provide personalized system solutions and corresponding technical services and support, including the following aspects: (1) providing system solution services: sub-module customization services and designing supporting solutions according to users' needs; (2) providing technical support resource packages, such as user manuals, FAQs, etc.; (3) providing remote consulting services: providing service consulting services through network instant calls, e-mails and service hotlines; (4) providing training services: providing lectures and trainings for learners, educators and related institutions, etc.

\section{Core technologies for innovation and entrepreneurship training based on wireless communication technology}

4.1 Cloud storage optimization technology based on wireless communication resources

For the wireless communication platform, as the number of users increases, it will certainly face the application bottleneck test of high concurrent access. Therefore, a fully distributed technical architecture is used to build a cloud storage solution for learning resources with high service efficiency, stable performance and reliability. At the same time, bi-directional transmission acceleration nodes are used to ensure that data upload and download speeds are optimized, thus greatly enhancing the efficiency of course content management and effectively reducing business management costs. It is one of the core technical issues that must be solved for the innovative and entrepreneurial talent training model based on wireless communication technology, as shown in Figure 3. 


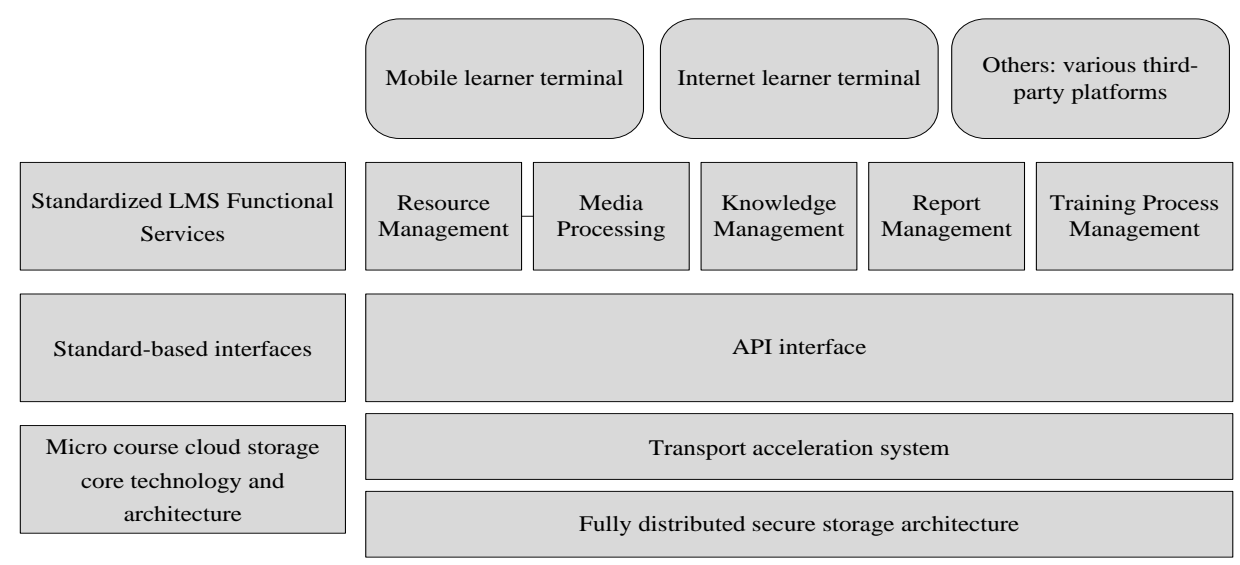

Figure 3 Cloud storage optimization technology diagram for learning resources

In addition, the easy-to-use, low-cost, flexible and scalable cloud storage optimization solution also ensures that users deploy only a small number of servers to record a small amount of metadata, fully protecting the user's internal core resources, thus minimizing the pressure on the user-side servers and facilitating the creation of an environmentally friendly service architecture. At the same time, the vast majority of micro-course on-demand or upload traffic is communicated directly from the client to the cloud storage platform, which maintains efficiency, reduces the client's own resource requirements, and prevents user-side data loss or leakage.

\subsection{Standards for development and management of educational resources}

Quality mobile education resource content is a key factor to ensure the success of the innovation and entrepreneurship talent training model. For WINNOVO Technology Co., Ltd, they have integrated more resources from government, schools and the community to jointly develop quality innovation and entrepreneurship resources, in addition to the relevant courses developed by their own team.

And to realize resource sharing, a "mobile micro-course resource development and management standard" with wide compatibility must first be designed to provide overall planning and specific instructions for the development standard framework, development specification, structured definition and other details of mobile micro-course, so as to maximize support for the construction of standardized micro-course content resources and the experience of offline learning users, as shown in Figure 4.

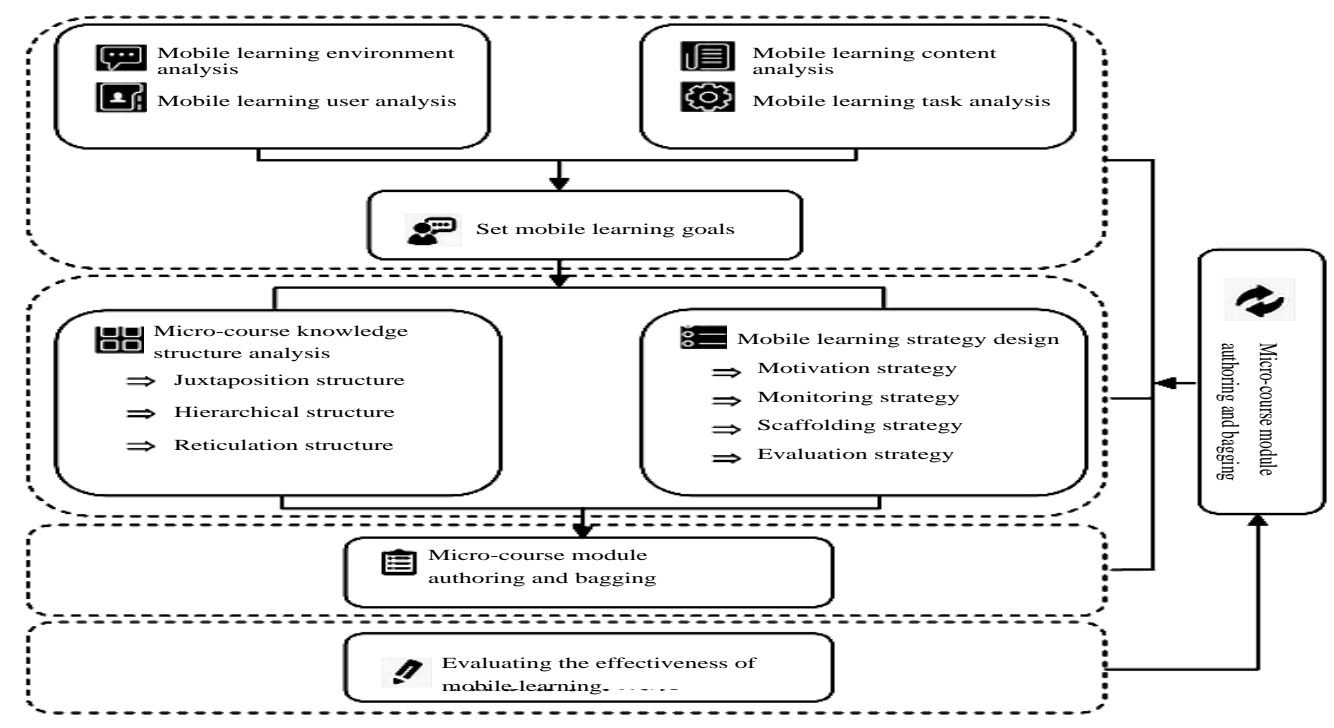

Figure 4Mobile micro-course resource development and management standards 
We believe that only after the standards for micro-course development and management are established can we effectively integrate various types of education and learning resources, thus maximizing resource sharing.

\section{Conclusion}

In this study, the wireless communication technology-based innovation and entrepreneurship talent cultivation model is an enterprise-level wireless communication service solution developed based on mobile Internet technology. It integrates big data technology, breaks through the traditional innovation and entrepreneurship education model, and creates a hybrid and intelligent learning management and knowledge management platform based on $\mathrm{O} 2 \mathrm{O}$. It is suitable for both individual learners and various enterprises, governments and educational institutions. Under the macro background of vigorously advocating the construction of the learning-oriented society and innovation and entrepreneurship education, the construction of high-quality learning platform and services will become a new starting point for the comprehensive social development of education and a powerful guarantee for "mass entrepreneurship and innovation", thus accelerating the process of cultivating innovative and entrepreneurial talents.

\section{Reference}

[1] Li Jiahua, Lu Xudong. Integrating innovation and entrepreneurship education into talent cultivation system in Colleges and universities [J]. Higher Education in China, 2010 (12): 9-11.

[2] Walnut, Shen Li. Enlightenment of Foreign Innovative and Entrepreneurial Education Model to Chinese Universities [J]. Teaching in Chinese Universities, 2013 (02): 92-96.

[3] Xu Detao. Research on Innovation and Entrepreneurship Education for Undergraduates [D]. Shandong University, 2013.

[4] Ma Xiaolong, Tao Yanyu. Construction and practice of core course teaching mode of innovation and entrepreneurship education based on information technology [J]. Modernization of education, 2019, 6 (25): $25-27$.

[5] Lu Xiaoqian. Exploring the path of innovation and entrepreneurship education based on "craftsman spirit"--Taking innovation and entrepreneurship work of Information Technology College of Wenzhou Vocational College of Science and Technology as an example[J]. Mass Science (Science Education), 2018,000 (007): 132-133.

[6] Deng Lidan. [J] Innovative entrepreneurship education model for IT students in Higher Vocational Colleges under the background of "China Intelligent Building". Industry and Technology Forum (12): 2.

[7] Qian Weifu. Exploration of innovative entrepreneurship education mode in Higher Vocational Colleges Based on "platform economy" with "two projects + two mentors"[J]. Guide to Economic Research, 2019, 399 (13): 178-180.

[8] Liu Yihua. Exploration and Analysis of Innovation and Entrepreneurship Education Path for Undergraduates in New Media Environment [J]. Heilongjiang Higher Education Research, 2016,000 (006): 94-96. 